\title{
Studies toward the synthesis of potencial artificial nucleases derived from trypargine
}

\author{
Rodrigo V. Pirovani and Ronaldo A. Pilli* \\ Instituto de Química - UNICAMP - Campinas, São Paulo, Brasil \\ *pill@iqm.unicamp.br
}

Keywords: $\beta$-carbolines, trypargine analogues, molecular recognition.

\section{INTRODUCTION}

The ability to efficiently hydrolyze nucleic acids in a biomimetic non-destructive process with high selectivity has become important because one can find many applications in structural design of new probes and drug development. This molecular recognition is a common feature in biological systems, where some functional groups form supramolecular systems by non-covalent interactions. For example, the guanidinium group present in the active site of the Staphylococcus nuclease is used to recognize the phosphodiester group, accelerating its hydrolysis. ${ }^{1}$

Recently, our group has synthesized the alkaloid tetrahydro- $\beta$-carboline (S)-(-)-trypargine (1) that presents a side chain at $\mathrm{C} 1$ with a terminal guanidine residue. ${ }^{2}$ Therefore, we decided to synthesize new derivatives of trypargine (2 and $\mathbf{3}$ ) in order to investigate their ability to recognize and trigger hydrolysis of phosphodiesters, such as DNA and RNA.
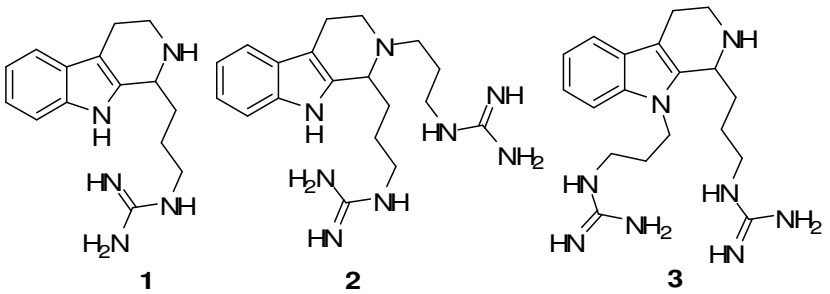

Figure 1. Trypargine (1) and analogues 2 and 3

\section{RESULTS AND DISCUSSION}

The synthesis of analogue 2 started with a three step procedure developed in our group, to build intermediate $\mathbf{6 .}^{2}$ Selective alkylation led to compound 7 , which was deprotected with $\mathrm{Pd} / \mathrm{C}$ and triethylsilane, providing the free diamine which was subjected to guanylation conditions (Scheme 1).

Analogue $\mathbf{3}$ was prepared by protecting tryptamine 8 in the form of a 2,5-dimethylpyrrol prior to Michael addition to acrylonitrile, leading to compound 9. Reduction of the nitrile gave the corresponding amine which was protected as a carbamate. Deprotection of the 2,5-dimethylpyrrol and coupling with Cbz-protected GABA, gave the advanced intermediate $\mathbf{1 1}$ in good yield over two steps (Scheme 2).

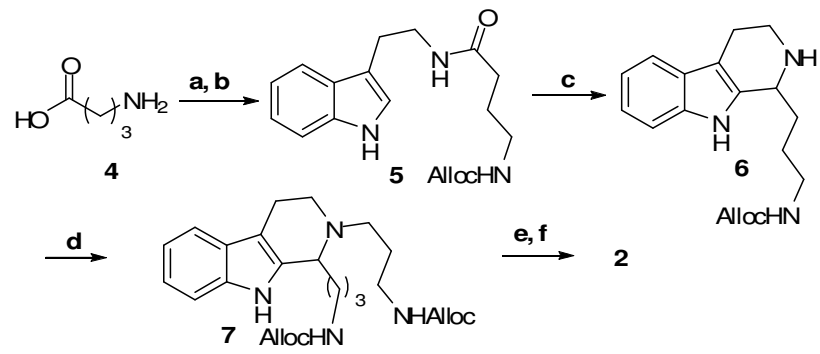

Reagents and conditions: a) Alloc-Cl, THF/ $\mathrm{NaHCO}_{3}$ solution (1:1), r.t., 24 h, 83\%; b) Tryptamine, EDC, HOBt, THF, r.t., 18 h, 97\%; c) (1) $\mathrm{POCl}_{3}$, PhMe/MeCN (7:3), reflux, 2 h; (2) $\mathrm{NaBH}_{4}, \mathrm{MeOH}, 0$ 으-r.t., 4 h, 69\%; d) allyl 3-bromopropylcarbamate, $\mathrm{K}_{2} \mathrm{CO}_{3}, \mathrm{MeCN}$, r.t., $12 \mathrm{~h}, 72 \%$; e) $\mathrm{Pd} / \mathrm{C} 10 \%$, $\mathrm{Et}_{3} \mathrm{SiH}, \mathrm{MeOH}$, r.t., $2 \mathrm{~h}, 45 \%$; f) $1 \mathrm{H}$-Pirazole carboxamidine, DIPEA, DMF, r.t., $24 \mathrm{~h}$.

Scheme 1. Preparation of analogue 2

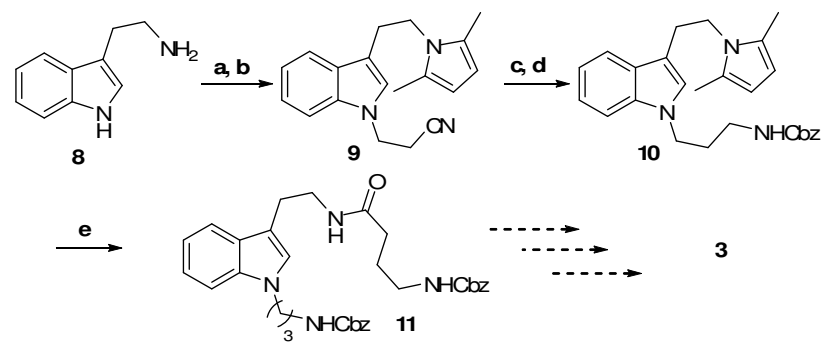

Reagents and conditions: a) 2,5-hexanedione, PhMe, reflux, 18h, 79\%; b) Acrilonitrile, DBU, MeCN, 16 h, 50 ○ C, 99\%; c) $\mathrm{LiAlH}_{4}$, THF, r.t., 7h, 68\%; d) Cbz-Cl, THF/ $\mathrm{Na}_{2} \mathrm{CO}_{3}$ solution (1:2), r.t., $24 \mathrm{~h}$, 95\%; e) (1) $\mathrm{NH}_{2} \mathrm{OH} . \mathrm{HCl}$, $\mathrm{Et}_{3} \mathrm{~N}$, Isopropanol $/ \mathrm{H}_{2} \mathrm{O}$ (3:1), reflux, $5 \mathrm{~h}$; (2) GABA-Cbz, EDC, HOBt, THF, r.t., $18 \mathrm{~h}, 52 \%$ (two steps).

Scheme 2. Preparation of analogue 3

Also, the study of interaction between trypargine 1 and bis(p-nitrophenyl)phosphate by calorimetric and NMR techniques is currently under investigation.

\section{CONCLUSION}

The synthetic route for the preparation of compound 2 has been well established, the deprotection of the Alloc group and final purification still requiring optimization. The strategy used for compound $\mathbf{3}$ is promising, with three steps remaining to achieve the target structure.

\section{ACKNOWLEDGEMENTS}

We thank Fapesp and CNPq.

\section{REFERENCES}

a) Cowan, J. A. Curr. Opin. Chem. Biol. 2001, 5, 634; b) Schug, K. A. Lindner, W. Chem. Rev. 2005, 105, 67.

Pilli, R. A.; Rodrigues Jr., M. T. J. Braz. Chem. Soc. 2009, 20, 1434. 